\title{
Comparison of the In Vivo Electrophysiological and Proarrhythmic Effects of Amiodarone With Those of a Selective Class III Drug, Sematilide, Using a Canine Chronic Atrioventricular Block Model
}

\author{
Hiroshi Yoshida, MD*; Atsushi Sugiyama, MD; Yoshioki Satoh, MD; \\ Yuko Ishida, PhD; Masahiko Yoneyama, MD; \\ Kiyotaka Kugiyama, MD*; Keitaro Hashimoto, MD
}

\begin{abstract}
Amiodarone effectively blocks both the sodium and calcium channels and $\beta$-adrenoceptors, in addition to blocking several potassium currents including IKr, Iкs, Ito, Iк1, IкACh and IкNa. The incidence of clinical torsade de pointes (TdP) associated with amiodarone has been reported to be low and the present study compared the proarrhythmic potential of amiodarone with that of a selective IKr channel blocker, sematilide, using a canine chronic atrioventrucular block model. Amiodarone or sematilide ( 3 and $30 \mathrm{mg} / \mathrm{kg} ; \mathrm{n}=4$ for each group) was administered orally without anesthesia under continuous ECG monitoring. Both drugs prolonged the QT interval, although the onset was faster for sematilide. The high dose of sematilide induced TdP in 3 of 4 animals, which caused their death, but neither the low dose of sematilide nor the 2 dosages of amiodarone induced lethal ventricular arrhythmias. These results suggest that IKr channel inhibition by amiodarone with its additional ion channel blocking action may contribute to the prevention of TdP. (Circ J 2002; 66: 758-762)
\end{abstract}

Key Words: Amiodarone; Atrioventrucular block; IKr channel; Sematilide; Torsade de pointes

A miodarone is generally classified as a VaughanWilliams class III agent ${ }^{1}$ and previous experimental studies have demonstrated that it effectively blocks the sodium and calcium channels and $\beta$-adrenoceptors as well as the IKr, IKs, Ito, IK1, IKACh and IKNa potassium channels (IKr: rapidly activating component of delayed rectifier $\mathrm{K}^{+}$current; IKs: slowly activating component of delayed rectifier $\mathrm{K}^{+}$current; Ito: transient outward $\mathrm{K}^{+}$ current; IK1: inward rectifier $\mathrm{K}^{+}$current; IKNa: $\mathrm{Na}^{+}$-activated $\mathrm{K}^{+}$current; IKACh: muscarinic acetylcholine receptor-operated $\mathrm{K}^{+}$current)! ${ }^{-9}$ Amiodarone is now considered one of the most promising drugs for the treatment of life-threatening ventricular tachyarrhythmias in patients with structural heart disease ${ }^{10-14}$ Nevertheless, as with other antiarrhythmic agents, torsade de pointes (TdP) following QT interval prolongation has been a concern during amiodarone therapy in the setting of bradyarrhythmias and hypokalemia, although the incidence of TdP associated with amiodarone therapy is reportedly low $!^{5-19}$ However, the extent of the in vivo proarrhythmic potential of amiodarone remains incompletely understood because of the scarcity of adequate experimental model systems.

The present study was designed to simultaneously assess the acute electrophysiological and proarrhythmic profiles of amiodarone using a canine chronic atrioventricular (AV)

(Received February 25, 2002; revised manuscript received May 9, 2002; accepted May 22, 2002)

Department of Pharmacology and *Second Department of Internal Medicine, Yamanashi Medical University, Yamanashi, Japan

Mailing address: Atsushi Sugiyama, MD, Department of Pharmacology, Yamanashi Medical University, Tamaho-cho, Nakakoma-gun, Yamanashi 409-3898, Japan. E-mail: atsushis@ res.yamanashi-med. ac.jp block model20,21 The model is a suitable large-animal model for the study of TdP because its hemodynamic status is stable despite an extreme bradycardia of 20 40 beats/min ${ }^{20-26}$ Previous studies have revealed the functional adaptations that predispose the canine AV block heart to acquired TdP;21-23,26 namely, the repolarization period is prolonged not only by the bradycardia but also by the reduction of the delayed rectifier potassium currents (IKr and Iks). We administered amiodarone orally without anesthesia under continuous ECG monitoring to better mimic the clinical therapy, and compared the results with those of a selective IKr channel blocker, sematilide? ${ }^{27-29}$

\section{Methods}

All experiments were carried out according to the Guidelines for Animal Experiments of Yamanashi Medical University. Beagle dogs of either sex weighing approximately $10 \mathrm{~kg}$ were obtained through the animal Laboratory for Research of Yamanashi Medical University.

\section{Production of Complete AV Block}

AV block was induced as previously described ${ }^{20}$ Briefly, the dogs were anesthetized with pentobarbital sodium $(30 \mathrm{mg} / \mathrm{kg}$, iv) and artificially ventilated with room air (Shinano, SN-480-3, Tokyo, Japan). Tidal volume and respiratory rate were set at $20 \mathrm{ml} / \mathrm{kg}$ and 15 strokes $/ \mathrm{min}$, respectively. Heparin calcium (200 IU $/ \mathrm{kg}$, iv) was administered to prevent blood clotting. The surface lead II ECG and systemic blood pressure at the right femoral artery were continuously monitored using a polygraph system (Nihon-Kohden, RM-6000, Tokyo, Japan) A quad-polar electrode catheter with a large tip of $4 \mathrm{~mm}$ (Cordis- 

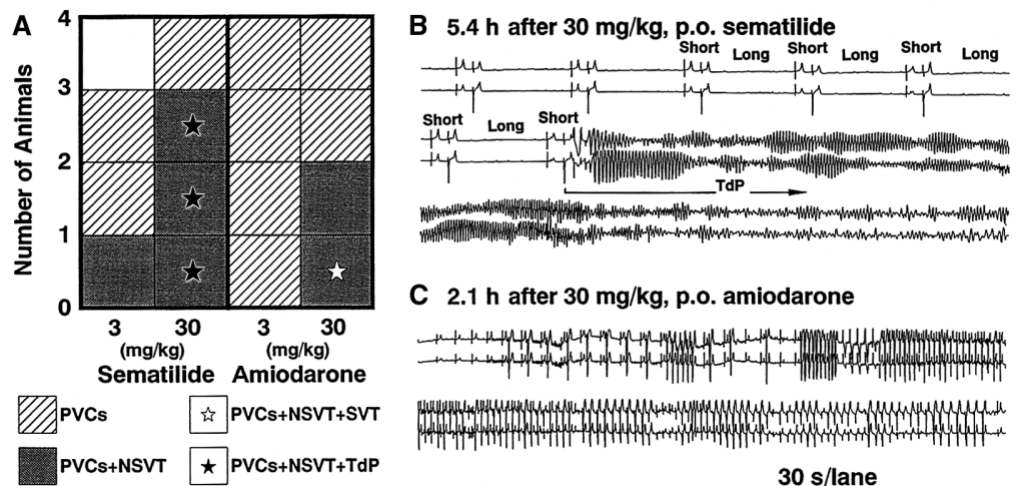

Fig 1. Comparison of the susceptibility for torsade de pointes (TdP) between the sematilide and amiodarone groups (A). Summary of the results. ECG of a chonic AV block animal complicated by (B) TdP after $30 \mathrm{mg} / \mathrm{kg}$ of sematilide and (C) by sustained ventricular tachycardia after $30 \mathrm{mg} / \mathrm{kg}$ of amiodarone. PVCs, premature ventricular contractions; NSVT, non-sustained $(<30 \mathrm{~s})$ ventricular tachycardia; SVT, sustained $(\geq 30 \mathrm{~s})$ ventricular tachycardia.
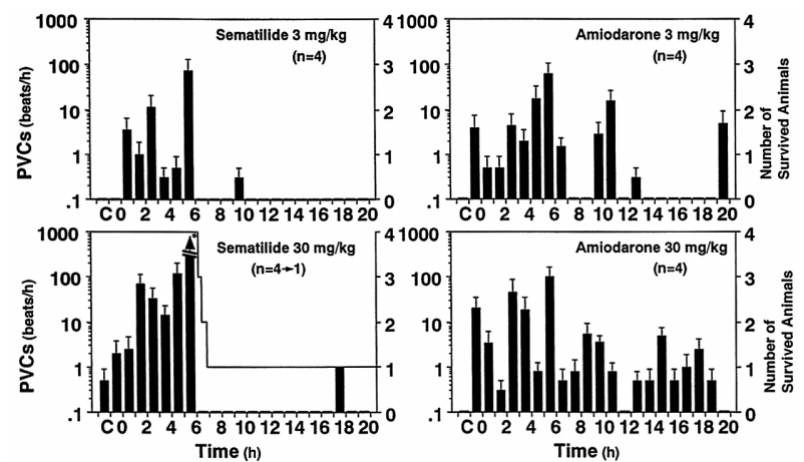

Fig 2. Time course of the number of premature ventricular contractions (PVCs) after administration of sematilide (Left) and amiodarone (Right). Data are presented as the mean \pm SE. Asterisks indicate statistically significant difference from each control value (C) by $\mathrm{p}<0.05$. The number of animals in the $30 \mathrm{mg} / \mathrm{kg}$ of sematilide group decreased from 4 to 1 because of death from torsade de pointes.

Webster, D7-DL-252, Baldwin Park, CA, USA) was inserted through the right femoral vein using a standard percutaneous technique ${ }^{30}$ under sterile conditions and positioned across the tricuspid valve under the guide of bipolar electrograms from the distal electrode pair. The optimal site for AV node ablation, namely the compact AV node, was determined on the basis of the intracardiac electrogram, on which a very small His deflection was recorded and the atrial/ventricular voltage ratio was greater than 2 . This site was usually found $1-2 \mathrm{~cm}$ proximal to where the largest His bundle electrogram was recorded. The power source for the AV node ablation was obtained from an electrosurgical generator (Mera, MS-1500, Tokyo, Japan), which delivered continuous unmodulated radiofrequency energy at a frequency of $500 \mathrm{kHz}$. After adequate localization, radiofrequency energy of $20 \mathrm{~W}$ was delivered for $10 \mathrm{~s}$ from the tip electrode to an indifferent patch electrode positioned on the animal's back, and then continued for $30 \mathrm{~s}$ if a junctional rhythm was induced. The endpoint of this procedure was the development of complete AV block with the onset of a stable idioventricular escaped rhythm (VR). More than 4 weeks after the induction of complete AV block, the following experiments were carried out.

\section{Continuous ECG Monitoring and Analysis}

A Holter recording system (Model 456A, Del Mar Avionics, Irvine, CA, USA) was used to monitor the ECG over $24 \mathrm{~h}^{20}$ and the ECG was analyzed with the Holter

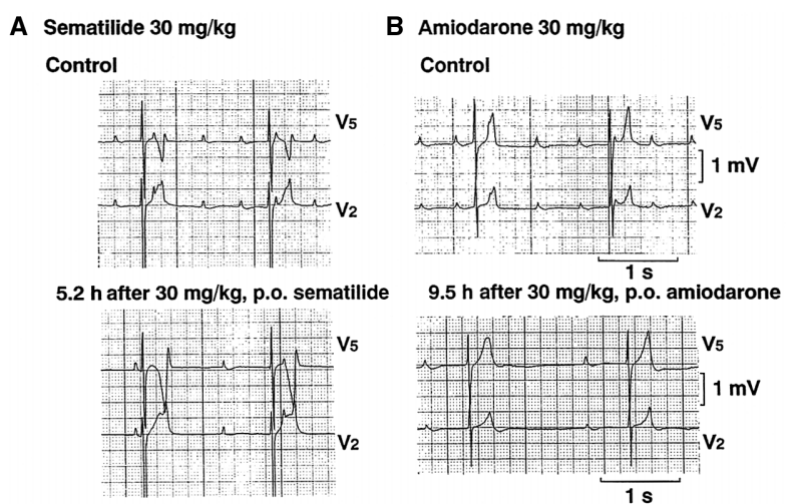

Fig 3. Typical ECG tracings before (Control) and after the administration of sematilide (A) and amiodarone (B). The recorded leads were bipolar electrograms. The negative electrode was positioned the manubrium of the sternum, and the positive electrode was placed on either the $\mathrm{V}_{2}$ position $\left(\mathrm{V}_{2}\right)$ or $\mathrm{V}_{5}$ position $\left(\mathrm{V}_{5}\right)$.

analyzing software (Protrack Model 563, Del Mar Avionics). The effects of the drugs on the VR, sinoatrial rate (SAR) and QT interval, as well as the proarrhythmic effects, were assessed. The SAR was calculated from the $\mathrm{P}-\mathrm{P}$ interval, and the $\mathrm{VR}$ from the $\mathrm{R}-\mathrm{R}$ interval. These values were expressed as the mean of 3 consecutive complexes. Ventricular premature contractions (PVCs) were defined as a premature depolarization of coupling interval $\leq 600 \mathrm{~ms}$ with prolonged, bizarre QRS complexes. Nonsustained ventricular tachycardia (VT) was defined as that which lasted more than than 4 consecutive beats at more than 100 beats/min and less than $30 \mathrm{~s}$, whereas sustained VT was that which lasted $30 \mathrm{~s}$ or more. TdP was defined as polymorphic VT, consisting of the QRS complexes of 6 beats or more twisting around the baseline? 1

\section{Experimental Protocol}

The 16 animals were randomly assigned to 4 groups: $3 \mathrm{mg} / \mathrm{kg} \quad(\mathrm{n}=4)$ and $30 \mathrm{mg} / \mathrm{kg}(\mathrm{n}=4)$ of sematilide, and $3 \mathrm{mg} / \mathrm{kg}(\mathrm{n}=4)$ and $30 \mathrm{mg} / \mathrm{kg}(\mathrm{n}=4)$ of amiodarone. The doses of sematilide and amiodarone used in this protocol were determined from previous reports to produce same degree of QT prolongation ${ }^{32-35}$ Approximately $2 \mathrm{~h}$ after the start of ECG monitoring, sematilide or amiodarone in gelatin capsules was administered orally and the ECG was recorded for at least $22 \mathrm{~h}$. The ECG values at $1 \mathrm{~h}$ before the drug administration were defined as the control (C) for each group. A volume of $2 \mathrm{ml}$ of venous blood was drawn 


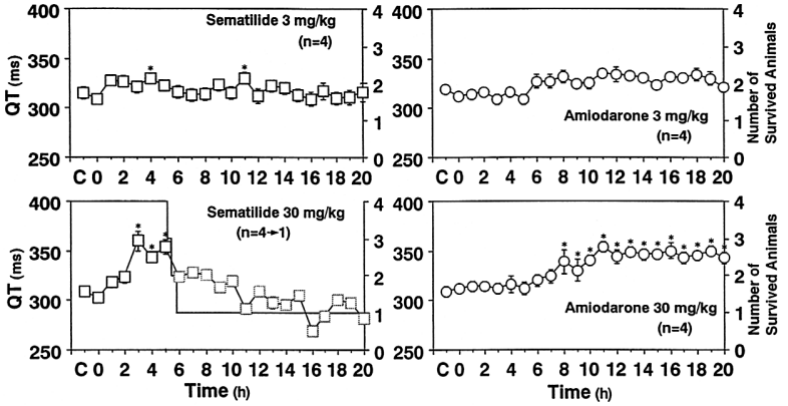

Fig 4. Time course of the QT interval after the administration of sematilide (Left) and amiodarone (Right). Data are presented as the mean \pm SE. Asterisks indicate statistically significant difference from each control value $(C)$ by $p<0.05$. Dashed symbols represent the result from one survived animal.

to measure the plasma concentration of amiodarone at $5 \mathrm{~h}$ after administration. The blood samples were centrifuged at $1,500 \mathrm{~g}$ for $30 \mathrm{~min}$ at $4^{\circ} \mathrm{C}$ and the plasma stored at $-80^{\circ} \mathrm{C}$ until the drug concentration was measured. Sensitive and specific determinations of the concentrations of amiodarone were performed at SRL Co, Ltd (Tokyo, Japan) using a standard high-performance liquid chromatographi method. The limit of quantification was $50 \mathrm{ng} / \mathrm{ml}$.

\section{Drugs and Statistics}

Sematilide was generously provided by Nippon Roussel (Tokyo, Japan) and the other drugs were purchased (amiodarone: Sigma, Tokyo, Japan; pentobarbital sodium: Tokyo Kasei, Tokyo, Japan; heparin calcium: Mitsui, Tokyo, Japan). Data are presented as the mean \pm SE. Differences within a parameter were assessed using one-way, repeatedmeasures ANOVA followed by Contrasts for the comparison of mean values. Meanwhile, those of unpaired data between the groups were evaluated by one-way, factorial ANOVA. A p value less than 0.05 was considered significant.

\section{Results}

\section{Comparison of the Proarrhythmic Effects (Fig 1)}

In the sematilide groups, PVCs were induced in 3 of 4 animals with the $3 \mathrm{mg} / \mathrm{kg}$ dose and in all animals with the $30 \mathrm{mg} / \mathrm{kg}$ dosage. Non-sustained VT was induced in 1 of 4 animals by the low dose and 3 of 4 by the high dose. Sustained VT was not observed in any animals with either dose, but TdP ( $>300$ beats $/ \mathrm{min}$ ) was induced in 3 of 4 animals by the high dose. The number of episodes of TdP recorded during the observation period was $1-5$ per animal. The onset of TdP was usually preceded by a characteristic sequence of short/long/short cycles of R waves (Fig 1B).

In the amiodarone groups, PVCs were induced in all animals by both the low dose of $3 \mathrm{mg} / \mathrm{kg}$ and the high dose of $30 \mathrm{mg} / \mathrm{kg}$. Neither non-sustained nor sustained VT was induced by the low dose, but the high dose induced nonsustained VT and sustained VT in 2 of 4 animals and in 1 of 4, respectively. These VTs were essentially monomorphic and did not degenerate into TdP (Fig 1C).

Time Course of the Number of PVCs (Fig 2)

The number of PVCs (beats/h) at the pre-drug control

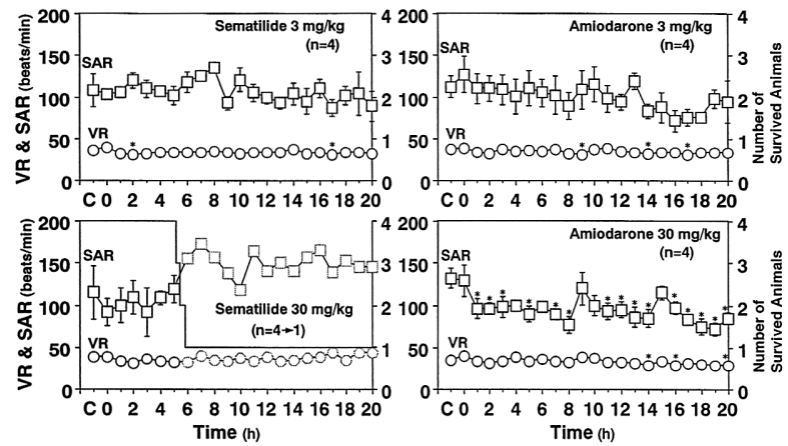

Fig 5. Time course of the idioventricular rate (VR; circles) and sinoatrial rate (SAR; squares) after the administration of sematilide (Left) and amiodarone (Right). Data are presented as the mean \pm SE. Asterisks indicate statistically significant difference from each control value $(\mathrm{C})$ by $\mathrm{p}<0.05$. Dashed symbols represent the result from one survived animal.

(C) was $0 \pm 0$ in the low-dose sematilide group and $2 \pm 2$ in the high-dose group, compared with $4 \pm 4$ in the low-dose amiodarone group and $21 \pm 14$ in the high-dose amiodarone group. There was no significant difference in the control values of the 4 groups.

In the low-dose sematilide group, PVCs tended to increase for 5-6h, but the change did not achieve statistical significance. In the high-dose sematilide group, the number of PVCs increased significantly for 5-6h and both TdP and non-sustained VT were observed during this time. We often could not count the precise number of PVCs during $\mathrm{TdP}$ and ventricular fibrillation because of the absence of clearly defined QRS complexes and in those cases we tentatively defined the number of PVCs as 5 beats/s. The initial TdP episode was observed $5.3 \pm 0.2 \mathrm{~h}(\mathrm{n}=3)$ after high-dose sematilide administration, and the last episode led to ventricular fibrillation and the animal's death at $5.4 \pm 0.2 \mathrm{~h}(\mathrm{n}=3)$ after drug administration.

There was no change in the number of PVCs after lowor high-dose amiodarone. Each VT episode was observed during the 2-6h after the high dose, and the peak number of PVCs was 5-6h after administration for both doses. The plasma drug concentration at $5 \mathrm{~h}$ after $3 \mathrm{mg} / \mathrm{kg}$ and $30 \mathrm{mg} / \mathrm{kg}$ of amiodarone was $<50 \mathrm{ng} / \mathrm{ml}$ and $1,083 \pm 188 \mathrm{ng} / \mathrm{ml}$, respectively.

Time Course of the Effects on ECG Parameters (Figs 3-5)

The QT interval (ms) at the pre-drug control (C) was $315 \pm 6$ in the low-dose sematilide group and $309 \pm 5$ in the high-dose group, compared with $319 \pm 2$ in the low-dose amiodarone group and $309 \pm 5$ in the high-dose amiodarone group. VR (beats/min) and SAR (beats/min) at the pre-drug control (C) were $36 \pm 2$ and $108 \pm 20$, respectively, in the low-dose sematilide group, and $38 \pm 2$ and $115 \pm 32$, respectively, with the high-dose of sematilide compared with $37 \pm 2$ and $112 \pm 13$ in the low-dose amiodarone group and $35 \pm 2$ and $132 \pm 2$ in the high-dose amiodarone group. There was no significant difference in the control values of the 4 groups (Fig 3).

After sematilide administration, the QT interval was significantly prolonged at $4 \mathrm{~h}$ and $11 \mathrm{~h}$ after the low dose and for 3-5 h after the high dose (Fig 4). VR was decreased by the low dose and a significant change was detected at $2 \mathrm{~h}$ and $17 \mathrm{~h}$ after administration; however, no significant change in VR was detected after the high dose, possibly 
because of the limited number of animals that survived (Fig 5). No significant change in SAR was observed after the low or high.

In the amiodarone group, the QT interval was gradually but significantly prolonged only after the high dose and a significant change was detected for 8-20h (Fig 4). VR was decreased by the low and high dose: a significant decrease was detected at 9,14 and $17 \mathrm{~h}$ after the low dose and at 14 , 16 and $20 \mathrm{~h}$ after the high dose. No significant change in SAR was observed after the low dose, but it was decreased by the high dose. Significant changes were detected for $1-3 \mathrm{~h}$, at $5 \mathrm{~h}$, for $7-8 \mathrm{~h}, 11-14 \mathrm{~h}$ and $16-20 \mathrm{~h}$ after drug administration.

\section{Discussion}

We characterized the in vivo electrophysiological and proarrhythmic effects of amiodarone in comparison with those of sematilide, a selective IKr channel blocker, using a canine chonic AV block model. The chonic bradycardia of this model facilitates the induction of lethal ventricular tachyarrhythmias, including $\mathrm{TdP}$, through electrophysiological and morphological remodeling of the heart ${ }^{22,23,26}$ As clearly shown in the present results, the high dose of sematilide induced TdP following QT prolongation and led to the death of 3 of 4 animals $(75 \%)$. In contrast, amiodarone induced sustained VT in only one animal (25\%) and although it prolonged the QT interval, no lethal arrhythmias were observed. These results are essentially in accordance with most of the previous knowledge from animal and clinical studies ${ }^{15-18,36-39}$

The plasma drug concentration at $5 \mathrm{~h}$ after $30 \mathrm{mg} / \mathrm{kg}$ of amiodarone was approximately $1 \mu \mathrm{g} / \mathrm{ml}$ in this study, suggesting that a clinically, and experimentally, expected antiarrhythmic plasma concentration can be obtained with oral administration! Thus, the currently observed effects of amiodarone may in part reflect the cardiovascular profile at sub-therapeutic to therapeutic levels of plasma drug concentration.

We demonstrated that a single oral dose of sematilide or amiodarone can prolong the QT interval, with a faster onset speed for sematilide than for amiodarone, possibly reflecting the difference in the pharmacokinetic properties of these drugs. The prolongation of the QT interval can be largely explained by their previously demonstrated IKr channel inhibition, ${ }^{2,28}$ because $\mathrm{IKr}$ is one of the major outward currents that determine the duration of the repolarization phase of the ventricle. In addition, amiodarone inhibits the other outward potassium currents, including IK1, IKs, IKNa, IKACh and Ito? Thus, further in vitro studies are needed to analyze the role of these repolarizing currents for QT interval prolongation in the currently used chonic AV block model.

Amiodarone exerted a negative chonotropic effect, whereas sematilide hardly affected the SAR. The lack of negative chonotropic effects of sematilide suggests that IKr inhibition itself may not be enough to induce bradycardia in the present canine chonic AV block model. On the other hand, amiodarone has been reported to possess a calcium channel blocking effect and a non-competitive weak $\beta$ blocking action at the plasma concentration reached in the present experiment, ${ }^{1,3-5,7}$ which would be a possible mechanism of the observed negative chonotropic effect.

The most important finding in this study is that sematilide induced $\mathrm{TdP}$, but amiodarone did not. It has been shown that IKr and IKs are down-regulated in the ventricles of the canine chonic AV block model, leading to less repolarization reserve ${ }^{26}$ In the presence of such a labile repolarization process, amiodarone induced only 1 episode of sustained VT, which did not degenerate into TdP (Fig 1C), although it prolonged QT interval in a similar fashion to sematilide. These results support in part our recent hypothesis regarding the antiarrhythmic mechanism of acute amiodarone ${ }^{7}$ and the proarrhythmic effects of sematilide; 40 that is, the antiarrhythmic effects of acute amiodarone depends on the combination of use-dependent sodium channel inhibition and reverse use-dependent potassium channel blockade, which shortens the electrically vulnerable period of the ventricle to provide postrepolarization refractoriness during tachycardia, leading to termination of re-entry arrhythmia? Prolongation of the terminal repolarization process (phase 3 repolarization) by sematilide would enhance the chance of conduction slowing at less complete repolarization levels and may be associated with its high incidence of TdP induction. ${ }^{40}$ However, further in vivo electrophysiological analysis is required, including the QT interval dispersion as well as transmural dispersion, to better understand the difference in the proarrhythmic potential of these drugs.

In summary, amiodarone did not induce lethal ventricular arrhythmias in the canine chonic AV block model, making it a more desirable choice than sematilide. IKr channel inhibition with additional ion channel blocking actions of amiodarone may contribute to its less proarrhythmic profile.

\section{Acknowledgments}

The authors thank Miss E. Tatsuzawa and Mr Y. Nakamura for their skillful technical assistance.

\section{References}

1. Harris L, Roncucci R. Amiodarone. Paris: Médecine et Sciences Internationales; 1986.

2. Kodama I, Kamiya K, Toyama J. Cellular electropharmacology of amiodarone. Cardiovasc Res 1997; 35: 13-29.

3. Awaji T, Wu ZJ, Hashimoto K. Acute antiarrhythmic effects of intravenously administered amiodarone on canine ventricular arrhythmia. J Cardiovasc Pharmacol 1995; 26: 869-878.

4. Nishimura M, Follmer CH, Singer DH. Amiodarone blocks calcium current in single guinea pig ventricular myocytes. J Pharmacol Exp Ther 1989; 251: 650-659.

5. Charlier R. Cardiac actions in the dog of a new antagonist of adrenergic excitation which does not produce competitive blockade of adrenoceptors. Br J Pharmacol 1970; 39: 668-674.

6. Follmer CH, Aomine M, Yeh JZ, Singer DH. Amiodarone-induced block of sodium current in isolated cardiac cells. J Pharmacol Exp Ther 1987; 243: 187-194.

7. Sugiyama A, Satoh Y, Hashimoto K. Acute electropharmacological effects of intravenously administered amiodarone assessed in the in vivo canine model. Jpn J Pharmacol 2001; 87: 74-82.

8. Pallandi RT, Campbell TJ. Resting, and rate-dependent depression of $\mathrm{V}_{\max }$ of guinea-pig ventricular action potentials by amiodarone and desethylamiodarone. Br J Pharmacol 1987; 92: 97-103.

9. Yabek SM, Kato R, Singh BN. Effects of amiodarone and its metabolite, desethylamiodarone, on the electrophysiological properties of isolated cardiac muscle. J Cardiovasc Pharmacol 1986; 8: 197-207.

10. Julian DG, Camm AJ, Frangin G, Janse MJ, Munoz A, Schwartz PJ, et al. Randomised trial of effect of amiodarone on mortality in patients with left-ventricular dysfunction after recent myocardial infarction: EMIAT. Lancet 1997; 349: 667-674.

11. Cairns JA, Connolly SJ, Roberts R, Gent M, for the Canadian Amiodarone Myocardial Infarction Arrhythmia Trial Investigators. Randomised trial of outcome after myocardial infarction in patients with frequent or repetitive ventricular premature depolarisations: CAMIAT. Lancet 1997; 349: 675-682. 
12. Amiodarone Trials Meta-Analysis Investigators. Effect of prophylactic amiodarone on mortality after acute myocardial infarction and in congestive heart failure: Meta-analysis of individual data from 6500 patients in randomised trials. Lancet 1997; 350: $1417-1424$.

13. Doval HC, Nul DR, Grancelli HO, Perrone SV, Bortman GR, Curiel $\mathrm{R}$, for Grupo de Estudio de la Sobrevida en la Insuficiencia Cardiaca en Argentina (GESICA). Randomised trial of low-dose amiodarone in severe congestive heart failure. Lancet 1994; 344: 493-498.

14. Aiba T, Kurita T, Taguchi A, Shimizu W, Suyama K, Aihara N, et al. Long-term efficacy of empirical chonic amiodarone therapy in patients with sustained ventricular tachyarrhythmia and structural heart disease. Circ J 2002; 66: 367-371.

15. Brown MA, Smith WM, Lubbe WF, Norris RM. Amiodaroneinduced torsades de pointes. Eur Heart J 1986; 7: 234-239.

16. Sclarovsky S, Lewin RF, Kracoff O, Strasberg B, Arditti A, Agmon J. Amiodarone-induced polymorphous ventricular tachycardia. Am Heart J 1983; 105: 6-12.

17. Skanes AC, Morton BC, Green MS, Tang AS. Torsade de pointes with amiodarone in a patient with previous torsade during betareceptor blockade. Can J Cardiol 1997; 13: 383-386.

18. Hohnloser SH, Klingenheben T, Singh BN. Amiodarone-associated proarrhythmic effects: A review with special reference to torsade de pointes tachycardia. Ann Intern Med 1994; 121: 529-535.

19. Yamada S, Kuga K, Yamaguchi I. Torsade de pointes induced by intravenous and long-term oral amiodarone therapy in a patient with dilated cardiomyopathy. Jpn Circ J 2001; 65: 236-238.

20. Chiba K, Sugiyama A, Satoh Y, Shiina H, Hashimoto K. Proarrhythmic effects of fluoroquinolone antibacterial agents: In vivo effects as physiologic substrate for Torsades. Toxicol Appl Pharmacol 2000; 169: 8-16.

21. Sugiyama A, Ishida Y, Satoh Y, Aoki S, Hori M, Akie Y, et al. Electrophysiological remodeling of the heart to AV block enhances susceptibility to arrhythmogenic effects of QT-prolonging drugs. Jpn J Pharmacol 2002; 88: $341-350$.

22. Volders PGA, Sipido KR, Vos MA, Kulcsár A, Verduyn SC, Wellens HJJ. Cellular basis of biventricular hypertrophy and arrhythmogenesis in dogs with chonic complete atrioventricular block and acquired torsade de pointes. Circulation 1998; 98: 1136-1147.

23. Vos MA, de Groot SHM, Verduyn SC, van der Zande J, Leunissen HDM, Cleutjens JPM, et al. Enhanced susceptibility for acquired torsade de pointes arrhythmias in the dog with chonic, complete AV block is related to cardiac hypertrophy and electrical remodeling. Circulation 1998; 98: 1125-1135.

24. Weissenburger J, Chezalviel F, Davy JM, Lainée P, Guhennec C, Penin E, et al. Methods and limitations of an experimental model of long QT syndrome. J Pharmacol Methods 1991; 26: 23 -42.

25. Weissenburger J, Davy JM, Chézalviel F, Ertzbischoff O, Poirier JM, Engel F, et al. Arrhythmogenic activities of antiarrhythmic drugs in conscious hypokalemic dogs with atrioventricular block: Comparison between quinidine, lidocaine, flecainide, propranolol and sotalol. J Pharmacol Exp Ther 1991; 259: 871-883.

26. Vorders PGA, Sipido KR, Vos MA, Spätjens RLHMG, Leunissen JDM, Carmeliet E, et al. Downregulation of delayed rectifier $\mathrm{K}^{+}$ currents in dogs with chonic complete atrioventricular block and acquired torsades de pointes. Circulation 1999; 100: 2455-2461.

27. Yamada A, Motomura S, Hashimoto K. Comparison of direct negative chonotropic and positive inotropic effects of sematilide to those of E-4031 and MS-551 and the reverse frequency-dependent prolongation of cardiac refractoriness of sematilide. J Cardiovasc Pharmacol 1996; 27: 159-166.

28. Sawanobori T, Adaniya H, Namiki T, Hiraoka M. Rate-dependent effects of sematilide on action potential duration in isolated guinea pig ventricular myocytes. J Pharmacol Exp Ther 1994; 271: $302-$ 310.

29. Beatch GN, Davis DR, Laganière S, Williams BA. Rate-dependent effects of sematilide on ventricular monophasic action potential duration and delayed rectifier $\mathrm{K}^{+}$current in rabbits. $J$ Cardiovasc Pharmacol 1996; 28: 618-630.

30. Baim DS, Grossman W. Percutaneous approach including transseptal and apical puncture. In: Baim DS, editor. Cardiac catheterization, angiography, and intervention, 5th edn. Baltimore: Williams \& Wilkins; 1995: 57-81.

31. Satoh T, Zipes DP. Rapid rates during bradycardia prolong ventricular refractoriness and facilitate ventricular tachycardia induction with cesium in dogs. Circulation 1996; 94: 217-227.

32. Akie Y, Ni C, Aye NN, Xue YX, Hashimoto K. Proarrhythmic effects of four class III antiarrhythmic drugs, MS-551, sematilide, dofetilide and KCB328, examined using ambulatory ECG. Asia Pacific J Pharmacol 2000; 14: 101-109.

33. Sager PT, Nademanee K, Antimisiaris M, Pacifico A, Pruitt C, Godfrey R, et al. Antiarrhythmic effects of selective prolongation of refractoriness. Circulation 1993; 88: 1072-1082.

34. Sun W, Sarma JSM, Singh BN. Electrophysiological effects of Doronedarone (SR33589), a noniodinated benzofuran derivative, in the rabbit heart: Comparison with amiodarone. Circulation 1999; 100: $2276-2281$.

35. Waxman HL, Groh WC, Marchlinski FE, Buxton A, Sadowski LM, Horowitz LN, et al. Amiodarone for control of sustained ventricular tachycardia: Clinical and electrophysiologic effects in 51 patients. Am J Cardiol 1982; 50: 1066-1074.

36. Hohnloser SH. Proarrhythmia with class III antiarrhythmic drugs: Types, risks, and management. Am J Cardiol 1997; 80: 82G-89G.

37. Morgan JM, Lopes A, Rowland E. Sudden cardiac death while taking amiodarone therapy: The role of abnormal repolarization. Eur Heart J 1991; 12: 1144-1147.

38. Wong W, Pavlou HN, Birgersdotter UM, Hilleman DE, Mohiuddin SM, Roden DM. Pharmacology of the class III antiarrhythmic agent sematilide in patients with arrhythmias. Am J Cardiol 1992; 69: 206-212.

39. Carlsson L, Almgren O, Duker G. QTU-prolongation and torsades de pointes induced by putative class III antiarrhythmic agents in the rabbit: Etiology and interventions. J Cardiovasc Pharmacol 1990; 16: $276-285$.

40. Sugiyama A, Hashimoto K. Effects of selective IKr channel blocker sematilide on the relationship between ventricular repolarization, refractoriness and onset of torsade de pointes. Jpn J Pharmacol 2002; 88: $414-421$. 